\title{
Ultrasonically Assisted Synthesis of Aromatic Sulfonic Acids under Vilsmeier Haack Conditions in Acetonitrile Medium
}

\author{
Kamatala Chinna Rajanna*, Purugula Venkanna, Mukka Satish Kumar, Soma Ram Gopal \\ Department of Chemistry, Osmania University, Hyderabad, India \\ Email: *kcrajannaou@yahoo.com
}

Received August 20, 2012; revised September 25, 2012; accepted October 5, 2012

\begin{abstract}
Sulfonation of aromatic compounds (Phenols, Anilines) is triggered by Vilsmeier Haack (VH) reagent ( $\mathrm{DMF} / \mathrm{POCl}_{3}$ ) or $\left(\mathrm{DMF} / \mathrm{SOCl}_{2}\right)$ in the presence of $\mathrm{NaHSO}_{3}$ under Sonication and conventional stirred conditions at room temperature. The reactions afforded corresponding Sulfonic acid derivatives in very good yields. The results obtained under Sonication were enhanced when compared with the yields of the conventional method.
\end{abstract}

Keywords: Vilsmeier Haack (VH) Reagent; Sulfonation; $\mathrm{NaHSO}_{3}$; Sonication; Aromatic Compounds

\section{Introduction}

Aromatic sulfonation is an electrophilic substitution in which a hydrogen atom on arene is replaced by $\mathrm{SO}_{3} \mathrm{H}$ group [1]. Aromatic sulfonic acids are intermediates for the preparation of dyes and pharmaceuticals. These acids are much stronger acids than the corresponding carboxylic acids. For instance, p-toluene sulfonic acid (pKa of -2.8 ), is about a million times stronger acid than benzoic acid ( $\mathrm{pKa}$ of 4.2$)$; while methane sulfonic acid ( $\mathrm{pKa}=$ -1.9 ) is about one million times stronger acid than acetic acid. Even though both alkyl and aryl sulfonic acids are well known in literature, there has been an up surging interest in the synthetic chemistry of aromatic sulfonic acids most of the applications are associated with the aromatic derivatives. The amides of p-amino benzene sulfonic acid and related compounds are known to form a large group of sulfa drugs. Sulfonation is major industrial chemical process used to make a diverse range of products, color intensifiers, pigments, medicinal, pesticides and organic intermediates. Petroleum sulfonates are widely used as detergent additives in lubricating oils. Additionally, every year paper pulp produces about a half $(0.5)$ million metric tons of lignin sulfonates as a byproduct. Sulfonation of aniline produces p-amino benzene sulfonic acid or sulfanilic acid which is a zwitterion with an unusual high melting point. Sulfonation of polystyrene can be used to prepare sodium polystyrene sulfonates. Similar to other forms of molecular modification, sulfonation is also a vital procedure, and disruptions in the

"Corresponding author. process can have significant pathophysiological ramifications and developmental consequences. The addition of sulfonates creates a negatively charged molecular environment at any physiological $\mathrm{pH}$ that can induce conformational changes, alter solubility, and promote ionic interactions, all of which can significantly influences the biological activity [2,3]. Among various sulfonating agents sulfuric acid $[2,3]$, oleum $[4,5]$ and $\mathrm{SO}_{3}[6]$ are widely used, but some of them could cause polymer chain degradation during the reaction due to their high reactivity and toxicity level. The presence of oleum leads to more diacid formation than the use of sulfuric acid. $\mathrm{SO}_{3}$ is an aggressive electrophile (sulfonating agent) that rapidly reacts with any organic compound containing an electron donor group. A perusal of literature shows that sulfonation with $\mathrm{SO}_{3}$ is a difficult reaction to perform on an industrial scale because the reaction is rapid and highly exothermic; releasing approximately $380 \mathrm{~kJ} / \mathrm{kg}$ $\mathrm{SO}_{3}$ reacted. Most of the organic compounds form a black char on contact with pure $\mathrm{SO}_{3}$ due to the rapid reaction and heat evolution. Highly aggressive reactivity of $\mathrm{SO}_{3}$ could be controlled by diluting and/or complexing the $\mathrm{SO}_{3}$ to moderate reactivity level. Over the past decade, our group has also been actively involved in designing a variety of ecofriendly materials using micelleforming surfactants as catalysts and unconventional energy sources (such as microwave irradiation and ultrasound) to assist Vilsmeier-Haack $(\mathrm{VH})$ reactions $[7,8]$ and Hunsdiecker reactions $[9,10]$. Therefore, it has been proposed to develop an alternate path way for sulfonation of aromatic compounds using (DMF + Oxychloride) $/ \mathrm{NaHSO}_{3}$. 
And the reactions not only reduce the reaction times but also enhanced the yields under sonication (solution phase).

\section{Results and Discussion}

The Vilsmeier Haack (VH) reaction [11-25] is widely used for formylation. It can be applied to introduce an acetyl group on activated aromatic or hetero aromatic compounds, many other conversions can be achieved with this technology. It is one of the most versatile reactions in organic synthesis of aromatic Sulfonic acid derivatives. In general, $\left(\mathrm{DMF} / \mathrm{POCl}_{3}\right)$ or $\left(\mathrm{DMF} / \mathrm{SOCl}_{2}\right)$ are used to generate an iminium salt intermediate salt can be used in the synthesis of a large number of heterocyclic compounds. Recently our group reported that bromo derivatives with $\mathrm{KBr}$ or NBS and nitro derivatives with $\mathrm{KNO}_{3}$ or $\mathrm{NaNO}_{2}$ using Vilsmeier-Haack reagent [7,8]. Encouraged by this result, we tried to use $\mathrm{VH}$ reagent $\left(\mathrm{DMF} / \mathrm{SOCl}_{2}\right.$ and $\left.\mathrm{DMF} / \mathrm{POCl}_{3}\right)$ in presence of $\mathrm{NaHSO}_{3}$ for sulfonation reactions.

Aromatic compounds, such as phenols and amines, underwent sulfonation when treated by $\mathrm{VH}$ reagent (DMF/ $\mathrm{SOCl}_{2}$ and $\mathrm{DMF} / \mathrm{POCl}_{3}$ ) in the presence of $\mathrm{NaHSO}_{3}$, affording the corresponding aromatic sulfonic acid derivatives in good yields under conventional stirred conditions at room temperature. In this study, $\mathrm{NaHSO}_{3}$ were used as reagent for the generation of $\mathrm{SO}_{3} \mathrm{H}^{+}$ions.

To check the generality of the reaction an array of aromatic compounds were used as substrates as shown in Scheme 1.

The reaction rapidly afforded high yields of the corresponding Sulfonic acid derivatives. All the products were compared with physical data and analyzed by $1 \mathrm{H}$ NMR spectra with authentic samples. When aromatic phenols and amines were reacted with $\left(\mathrm{POCl}_{3}+\mathrm{DMF}\right)$ in the presence of $\mathrm{NaHSO}_{3}$, the reaction indicated corresponding sulfonic acid derivatives. Data summarized in Tables 1 and 2, clearly demonstrate that the reaction proceeded rapidly with $\left(\mathrm{POCl}_{3}+\mathrm{DMF}\right) / \mathrm{NaHSO}_{3}$ over $\left(\mathrm{SOCl}_{2}+\right.$ $\mathrm{DMF} / \mathrm{NaHSO}_{3}$ to afford high yields of the corresponding sulfonic acid derivatives. This may be because the active electrophile $\left(\mathrm{SO}_{3} \mathrm{H}^{+}\right)$is released faster in the case of the $\left(\mathrm{POCl}_{3}+\mathrm{DMF}\right) /\left(\mathrm{NaHSO}_{3}\right)$ system and is available for favorable Nitration over the $\left(\mathrm{SOCl}_{2}+\mathrm{DMF}\right) /\left(\mathrm{NaHSO}_{3}\right)$ system. The reaction of DMF with phosphorus and sulfur oxychlorides produces an electrophilic iminium cation. The ease of formation of such electrophilic iminium cation is faster with $\mathrm{POCl}_{3}$ than that with $\mathrm{SOCl}_{2}$ because $\mathrm{POCl}_{3}$ is relatively stronger Lewis acid than $\mathrm{SOCl}_{2}$. This could be attributed to the fact that phosphorus contains less electron density than sulfur and thus tends to have a faster tendency to bind with DMF than sulfur. The electrophilic iminium cation thus formed consequently forms $\mathrm{SO}_{3} \mathrm{H}^{+}$ion in the same order in presence of $\mathrm{NaHSO}_{3}$.

It is interesting to note that the reaction times under conventional stirred conditions are too long even though

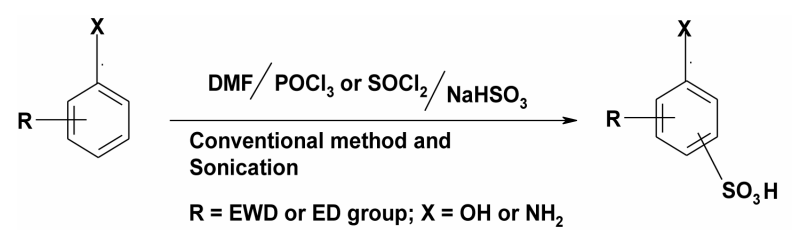

Scheme 1. Sulfonation of certain aromatic compounds using $\left(\mathrm{DMF} / \mathrm{POCl}_{3}\right.$ or $\left.\mathrm{SOCl}_{2}\right) / \mathrm{NaHSO}_{3}$.

Table 1. Sulfonation of certain aromatic compounds using (DMF $\left.+\mathrm{SOCl}_{2}\right) / \mathrm{NaHSO}_{3}$.

\begin{tabular}{clcccc}
\hline \multirow{2}{*}{ Entry } & \multirow{2}{*}{ Substrate } & \multicolumn{2}{c}{ Conventional method } & \multicolumn{2}{c}{ Sonication } \\
\cline { 3 - 6 } & & R.T (hrs) & Yield (\%) & R.T (hrs) & Yield (\%) \\
\hline 1 & Phenol & 6.0 & 85 & 3.0 & 88 \\
2 & 2-Cresol & 5.0 & 74 & 2.0 & 76 \\
3 & 4-Cresol & 5.5 & 76 & 2.0 & 80 \\
4 & 3-Cresol & 6.0 & 70 & 3.0 & 75 \\
5 & Aniline & 7.0 & 80 & 3.5 & 90 \\
6 & 4-Toluidine & 7.5 & 75 & 3.0 & 80 \\
7 & 2-Toluidine & 7.5 & 74 & 3.0 & 78 \\
8 & 2-OH Benzaldehyde & 8.5 & 70 & 4.0 & 78 \\
9 & 4-OH Benzaldehyde & 8.0 & 74 & 3.0 & 80 \\
10 & 2-Chloro thiophene & 8.0 & 70 & 4.5 & 82 \\
11 & Bromo Benzene & 7.5 & 76 & 3.0 & 80 \\
12 & Chloro Benzene & 6.5 & 78 & 2.0 & 84 \\
\hline
\end{tabular}


Table 2. Sulfonation of certain aromatic compounds using $\left(\mathrm{DMF}+\mathbf{P O C l}_{3}\right) / \mathrm{NaHSO}_{3}$.

\begin{tabular}{clcccc}
\hline \multirow{2}{*}{ Entry } & \multicolumn{2}{c}{ Substrate } & \multicolumn{2}{c}{ Conventional method } & \multicolumn{2}{c}{ Sonication } \\
\cline { 3 - 6 } & & R.T (hrs) & Yield (\%) & R.T (hrs) & Yield (\%) \\
\hline 1 & Phenol & 5.5 & 88 & 3.0 & 90 \\
2 & 2-Cresol & 5.0 & 76 & 2.5 & 78 \\
3 & 4-Cresol & 5.0 & 80 & 2.0 & 84 \\
4 & 3-Cresol & 6.0 & 75 & 3.0 & 78 \\
5 & Aniline & 6.5 & 82 & 3.5 & 92 \\
6 & 4-Toluidine & 7.0 & 75 & 3.5 & 80 \\
7 & 2-Toluidine & 7.0 & 75 & 3.0 & 80 \\
8 & 2-OH Benzaldehyde & 8.0 & 72 & 4.0 & 80 \\
9 & 4-OH Benzaldehyde & 7.5 & 76 & 3.0 & 82 \\
10 & 2-Chloro thiophene & 8.0 & 76 & 4.0 & 85 \\
11 & Bromo Benzene & 7.5 & 80 & 3.0 & 84 \\
12 & Chloro Benzene & 6.0 & 80 & 2.5 & 86 \\
\hline
\end{tabular}

the yields are fairly appreciative. However, the reaction times decreased substantially and rate enhancements were observed in the case of ultrasonically assisted reactions. The observed rate accelerations could be explained due to cavitation, a physical process that creates, enlarges, and implodes gaseous and vaporous cavities in an ultrasonically assisted (irradiated) liquid. Cavitation induces very high local temperatures in the reaction mixture and enhances mass transfer [26-28].

\section{Conclusion}

In summary, the authors developed a methodology for the synthesis of aromatic sulfonic acids using VilsmeierHaack Reagent/ $\mathrm{NaHSO}_{3}$ from aromatic compounds (Phenols and anilines) under Sonication and conventional stirred conditions. The developed protocol offered several advantages such as rate accelerations, excellent yields with simple work up procedure.

\section{Experimental Details}

All the solvents and chemicals were procured either from Aldrich, Merck, Loba or SD fine Chemicals. Progress of the reactions was monitored by thin layer chromatogramphy using Merck Silica gel 60 F254 pre-coated TLC plates. Ultrasonically assisted reactions were conducted in an Ultrasonic Sonicator bath (Bio-Technics, India: ISO. 9001-2000).

\subsection{General Procedure for the Preparation of Vilsmeier Haack Reagent}

The Vilsmeier Haack (VH) adduct is always prepared fresh from $\mathrm{POCl}_{3}$ (or $\mathrm{SOCl}_{2}$ ) and dimethyl formamide (DMF) at chilled temperatures. Chilled DMF (50.0 mmol) was added slowly and drop wise (at $-5^{\circ} \mathrm{C}$ ) to $\mathrm{POCl}_{3}$ or $\mathrm{SOCl}_{2}(50.0 \mathrm{mmol})$ in $50.0 \mathrm{~mL}$ acetonitrile $(\mathrm{Me} \mathrm{CN})$, under stirred conditions, which resulted in slurry indicating the formation of $\mathrm{VH}$ reagent. The reagent thus obtained is kept under cold conditions (at $-5^{\circ} \mathrm{C}$ ).

\subsection{General Procedure for the Synthesis of Aromatic Sulfonicacids Using Vilsmeier Haack Reagent under Conventional Method}

Organic substrate (phenols, anilines) (10.0 mmol), about $15.0 \mathrm{mmol}$ of $\mathrm{VH}$ reagent and $10.0 \mathrm{mmol} \mathrm{NaHSO}_{3}$ and $20.0 \mathrm{~mL}$ solvent (Me $\mathrm{CN}$ ) were taken in a previously cleaned in a round bottom flask and stirred for about 5 to 8 hours at room temperature. After completion of the reaction, as confirmed by $\mathrm{TLC}$, the reaction mixture is treated with $5 \%$ hypo solution, followed by the addition of ethyl acetate. The organic layer was separated, dried over $\mathrm{Na}_{2} \mathrm{SO}_{4}$ and the solvent is recollected by distillation using Rotavapor. The resultant compound was further purified with column chromatography using ethyl acetate: hexane $(7: 3)$ as eluent to get pure product. Hexane and ethyl acetate are also distilled using Rotavapor according to standard procedures.

\subsection{General Procedure for Ultrasonically Assisted Synthesis of Aromatic Sulfonic Acids Using Vilsmeier Haack Reagent}

For ultrasonically assisted synthesis of aromatic sulfonic 
acids the reaction flask containing organic substrate (phenols, anilines) (10.0 mmol), about $15.0 \mathrm{mmol}$ of $\mathrm{VH}$ reagent, $10.0 \mathrm{mmol}$ of $\mathrm{NaHSO}_{3}$ and $20.0 \mathrm{~mL}$ solvent (Me $\mathrm{CN}$ ) was placed in a Sonicator bath at room temperature. After completion of the reaction, as confirmed by TLC, the reaction mixture is further processed for the isolation of product as detailed in earlier section.

\subsection{Spectral Data of Certain Compounds}

4-Hydroxy Benzene Sulfonic Acid: ${ }^{1}$ H NMR: $7.23 \delta$ (5, $1 \mathrm{H}, \mathrm{dd} \mathrm{J}=7.0 \mathrm{~Hz}, \mathrm{~J}=1.5 \mathrm{~Hz}) 7.27 \delta(6,1 \mathrm{H}, \mathrm{dd}, \mathrm{J}=8.0$ $\mathrm{Hz}, \mathrm{J}=1.5 \mathrm{~Hz}), 7.78 \delta(7,1 \mathrm{H}, \mathrm{dd}, \mathrm{J}=8.0 \mathrm{~Hz}, \mathrm{~J}=1.0 \mathrm{~Hz})$, $7.94 \delta(8,1 \mathrm{H}, \mathrm{dd}, \mathrm{J}=8.0 \mathrm{~Hz}, \mathrm{~J}=1.5 \mathrm{~Hz}) 9.84 \delta(\mathrm{OH})$;

13C NMR: $158.56 \delta, 136.54 \delta, 127.22 \delta, 114.40 \delta$.

4-Amino Benzene Sulfonic Acid: ${ }^{1}$ H NMR: $7.04 \delta$ $(5,1 \mathrm{H}, \mathrm{dd}, \mathrm{J}=8.0 \mathrm{~Hz}, \mathrm{~J}=1 \mathrm{~Hz}), 7.21 \delta(6,1 \mathrm{H}, \mathrm{dd}, \mathrm{J}=$ $8.0 \mathrm{~Hz}, \mathrm{~J}=0.5 \mathrm{~Hz}), 7.92 \delta(7,1 \mathrm{H}, \mathrm{dd}, \mathrm{J}=8.0 \mathrm{~Hz}, \mathrm{~J}=0.5$ $\mathrm{Hz}), 7.91 \delta(8,1 \mathrm{H}, \mathrm{dd}, \mathrm{J}=8.0 \mathrm{~Hz}, \mathrm{~J}=0.5 \mathrm{~Hz}), 9.68 \delta(\mathrm{s}$ OH) $10.0 \delta(\mathrm{s} \mathrm{NH})$;

${ }^{13}$ CNMR: $146.5 \delta, 131.90 \delta, 126.90 \delta, 122.25 \delta$.

4-Chloro Benzene Sulfonic Acid: ${ }^{1}$ H NMR: $7.54 \delta$ $(5,1 \mathrm{H}, \mathrm{dd}, \mathrm{J}=8.0 \mathrm{~Hz}, \mathrm{~J}=0.5 \mathrm{~Hz}), 7.83 \delta(6,1 \mathrm{H}, \mathrm{dd}, \mathrm{J}=$ $8.0 \mathrm{~Hz}, \mathrm{~J}=0.5 \mathrm{~Hz}), 7.85 \delta(7,1 \mathrm{H}, \mathrm{dd}, \mathrm{J}=8.0 \mathrm{~Hz}, \mathrm{~J}=0.5$ $\mathrm{Hz}), 7.54 \delta(8,1 \mathrm{H}, \mathrm{dd}, \mathrm{J}=8.0 \mathrm{~Hz}, \mathrm{~J}=0.5 \mathrm{~Hz})$;

${ }^{13}$ C NMR: $142.05 \delta, 137.5 \delta, 130.00 \delta, 127.95 \delta$.

4-Bromo Benzene Sulfonic Acid: ${ }^{1}$ H NMR: $7.64 \delta$ (5, $1 \mathrm{H}, \mathrm{dd}, \mathrm{J}=8.0, \mathrm{~Hz} \mathrm{~J}=0.5 \mathrm{~Hz}), 7.65 \delta(6,1 \mathrm{H}, \mathrm{dd}, \mathrm{J}=8.0$ $\mathrm{Hz}, \mathrm{J}=0.5 \mathrm{~Hz}), 7.85 \delta(7,1 \mathrm{H}, \mathrm{dd}, \mathrm{J}=8.0 \mathrm{~Hz}, \mathrm{~J}=0.5 \mathrm{~Hz})$, $7.73 \delta(8,1 \mathrm{H}, \mathrm{dd}, \mathrm{J}=8.0 \mathrm{~Hz}, \mathrm{~J}=0.5 \mathrm{~Hz})$;

${ }^{13}$ C NMR: $139.25 \delta, 135.25 \delta, 130.00 \delta, 127.95 \delta$.

4-Toulidine, 2-Sulfonic Acid: ${ }^{1} \mathbf{H}$ NMR: $2.45 \delta(1$, $3 \mathrm{H}), 7.54 \delta(6,1 \mathrm{H}, \mathrm{dd}, \mathrm{J}=8.0 \mathrm{~Hz}, \mathrm{~J}=1.5 \mathrm{~Hz}), 7.13 \delta(7$, $1 \mathrm{H}, \mathrm{dd}, \mathrm{J}=8.0 \mathrm{~Hz}, \mathrm{~J}=0.5 \mathrm{~Hz}), 7.74 \delta(8,1 \mathrm{H}, \mathrm{dd}, \mathrm{J}=1.5$ $\mathrm{Hz}, \mathrm{J}=0.5 \mathrm{~Hz}$ );

${ }^{13}$ C NMR: $140.10 \delta, 137.85 \delta, 131.0 \delta, 127.95 \delta$, $125.25 \delta, 124.20 \delta, 20.50 \delta$.

2-Toluidine, 4-Sulfonic Acid: ${ }^{\mathbf{1}} \mathbf{H}$ NMR: $2.35 \delta$ (1, $3 \mathrm{H}), 7.12 \delta(6,1 \mathrm{H}, \mathrm{dd}, \mathrm{J}=8.0 \mathrm{~Hz}, \mathrm{~J}=0.5 \mathrm{~Hz}), 8.05 \delta(7$, $1 \mathrm{H}, \mathrm{dd}, \mathrm{J}=8.0 \mathrm{~Hz}, \mathrm{~J}=2.0 \mathrm{~Hz}), 7.12 \delta 8(8,1 \mathrm{H}, \mathrm{dd}, \mathrm{J}=$ $2.0 \mathrm{~Hz} \mathrm{~J}=0.5 \mathrm{~Hz}$ );

${ }^{13}$ C NMR: $146.65 \delta, 131.60 \delta, 130.80 \delta, 128.25 \delta$, $124.15 \delta, 122.20 \delta, 16.70 \delta$.

p-Toluene Sulfonic Acid: ${ }^{\mathbf{1}} \mathbf{H}$ NMR: $1.67 \delta(1,3 \mathrm{H})$, $6.66 \delta(5,1 \mathrm{H}, \mathrm{dd}, \mathrm{J}=8.0 \mathrm{~Hz}, \mathrm{~J}=0.5 \mathrm{~Hz}), 6.66 \delta(6,1 \mathrm{H}$, $\mathrm{dd}, \mathrm{J}=8.0 \mathrm{~Hz}, \mathrm{~J}=0.5 \mathrm{~Hz}), 7.12 \delta(7,1 \mathrm{H}, \mathrm{dd}, \mathrm{J}=8.0 \mathrm{~Hz}$, $\mathrm{J}=0.5 \mathrm{~Hz}), 7.10 \delta(8,1 \mathrm{H}, \mathrm{dd}, \mathrm{J}=8.0 \mathrm{~Hz}, \mathrm{~J}=05 \mathrm{~Hz})$;

${ }^{13}$ CNMR: $141.99 \delta, 139.02 \delta, 129.05 \delta, 124.94 \delta, 20.13 \delta$.

4-Hydroxy-3-methylbenzenesulfonic Acid: ${ }^{1}$ H NMR: $2.45 \delta(1,3 \mathrm{H}), 7.04 \delta(6,1 \mathrm{H}, \mathrm{dd}, \mathrm{J}=8.0 \mathrm{~Hz}, \mathrm{~J}=0.5 \mathrm{~Hz})$, $7.05 \delta(7,1 \mathrm{H}, \mathrm{dd}, \mathrm{J}=8.0 \mathrm{~Hz}, \mathrm{~J}=2.0 \mathrm{~Hz}), 7.95 \delta(8,1 \mathrm{H}$, $\mathrm{dd}, \mathrm{J}=2.0 \mathrm{~Hz}, \mathrm{~J}=0.5 \mathrm{~Hz}$ );

${ }^{13}$ C NMR: $156.5 \delta, 136.35 \delta, 128.23 \delta, 124.45 \delta, 123.25$ $\delta, 113.65 \delta, 15.75 \delta$.
2-Hydroxy-5-methylbenzenesulfonic Acid: ${ }^{\mathbf{1}} \mathrm{H}$ NMR: $2.45 \delta(1,3 \mathrm{H}), 6.94 \delta(6,1 \mathrm{H}, \mathrm{dd}, \mathrm{J}=8.0 \mathrm{~Hz}, \mathrm{~J}=1.0 \mathrm{~Hz})$, $7.0 \delta(7,1 \mathrm{H}, \mathrm{dd}, \mathrm{J}=8.0 \mathrm{~Hz}, \mathrm{~J}=0.5 \mathrm{~Hz}), 7.75 \delta(8,1 \mathrm{H}$, $\mathrm{dd}, \mathrm{J}=10 \mathrm{~Hz}, \mathrm{~J}=0.5 \mathrm{~Hz}$ );

${ }^{13}$ C NMR: $147.25 \delta, 128.35 \delta, 126.52 \delta, 122.83 \delta$, $120.35 \delta, 117.56 \delta, 18.42 \delta$.

4-Hydroxy-2-methylbenzenesulfonic Acid: ${ }^{\mathbf{1}}$ H NMR: $2.35 \delta(1,3 \mathrm{H}), 7.04 \delta(6,1 \mathrm{H}, \mathrm{dd}, \mathrm{J}=8.0 \mathrm{~Hz}, \mathrm{~J}=3.0 \mathrm{~Hz})$, $7.96 \delta(7,1 \mathrm{H}, \mathrm{dd}, \mathrm{J}=8.0 \mathrm{~Hz}, \mathrm{~J}=1.0 \mathrm{~Hz}), 7.02 \delta(8,1 \mathrm{H}$, $\mathrm{dd}, \mathrm{J}=3.0 \mathrm{~Hz} \mathrm{~J}=1.0 \mathrm{~Hz}$ );

${ }^{13}$ C NMR: $158.36 \delta, 134.28 \delta, 125.26 \delta, 128.76 \delta$, $125.65 \delta, 113.92 \delta, 20.82 \delta$.

3-Formyl-4-hydroxybenzenesulfonic Acid: ${ }^{\mathbf{1}} \mathbf{H}$ NMR: $10.01 \delta(6,1 \mathrm{H}), 7.28 \delta(7,1 \mathrm{H}, \mathrm{dd}, \mathrm{J}=8.0 \mathrm{~Hz}, \mathrm{~J}=2.0 \mathrm{~Hz})$, $7.85 \delta(8,1 \mathrm{H}, \mathrm{dd}, \mathrm{J}=8.0 \mathrm{~Hz}, \mathrm{~J}=2.0 \mathrm{~Hz}), 8.74 \delta(9,1 \mathrm{H}$, $\mathrm{dd}, \mathrm{J}=2.0 \mathrm{~Hz}, \mathrm{~J}=2.0 \mathrm{~Hz}) 10.25 \delta(\mathrm{s} \mathrm{OH})$;

${ }^{13}$ C NMR: $135.45 \delta, 168.65 \delta, 135.56 \delta, 125.95 \delta$, $138.82 \delta, 117.75 \delta, 190.12 \delta$.

5-Formyl-2-hydroxybenzenesulfonic Acid: ${ }^{\mathbf{1}} \mathbf{H}$ NMR: $10.02 \delta(6,1 \mathrm{H}), 7.24 \delta(7,1 \mathrm{H}, \mathrm{dd}, \mathrm{J}=8.0 \mathrm{~Hz}, \mathrm{~J}=1.0 \mathrm{~Hz})$, $7.63 \delta(8,1 \mathrm{H}, \mathrm{dd}, \mathrm{J}=7.0 \mathrm{~Hz}, \mathrm{~J}=1.5 \mathrm{~Hz}), 8.75 \delta(9,1 \mathrm{H}$, $\mathrm{dd}, \mathrm{J}=1.5 \mathrm{~Hz}, \mathrm{~J}=0.5 \mathrm{~Hz}) 9.98 \delta(\mathrm{s} \mathrm{OH})$;

${ }^{13}$ C NMR: $135.25 \delta, 159.75 \delta, 130.25 \delta, 117.75 \delta$, $139.25 \delta, 190.12 \delta$.

\section{REFERENCES}

[1] J. March, "Advanced Organic Chemistry: Reactions, Mechanisms, and Structure," 3rd Edition, Wiley, New York, 1985.

[2] R. Piria, "Ueber Einige Produkte der Einwirkung des Schwefligsauren Ammoniaks auf Nitronaphtalin," Artificial Neural Network, Vol. 78, 1851, pp. 31-68.

[3] W. H. Hunter and M. M. Sprung, "The Piria Reaction. I. The Over-All Reaction," Journal of the American Chemical Society, Vol. 53, No. 4, 1931, pp. 1432-1443. doi:10.1021/ja01355a037

[4] H. Aleboyeh, S. Walter, A. Aleboyeh and N. Ladhari, "Naphthalenedisulphonic Acid Formation with 20 Oleum," Organic Process Research \& Development, Vol. 1, No. 6, 1997, pp. 411-414. doi:10.1021/op9700237

[5] E. E. Gilbert, "Sulfonation and Related Reactions," R. E. Krieger Publishing Company, New York, 1977, p. 81.

[6] E. E. Gilbert, B. Veldhuis, E. J. Carlson and H. R. Nychka, "Sulfonation with Sulfur Trioxide," ESG Chemistry, Vol. 45, 1953, p. 2065.

[7] A. Chakradhar, R. Roopa, K. C. Rajanna and P. K. Saiprakash, "Vilsmeier-Haack Bromination of Aromatic Compounds with $\mathrm{KBr}$ and N-Bromosuccinimide under Solvent-Free Conditions," Synthetic Communications, Vol. 39, No. 10, 2009, pp. 1817-1824.

[8] K. C. Rajanna, M. Satish Kumar, P. Venkanna, S. Ramgopal and M. Venkateswarlu, " Vilsmeier Haack Adducts as Effective Reagents for Regioselective Nitration of Aromatic Compounds under Conventional and NonConventional Conditions" International Joural of Orga- 
nic Chemistry, Vol. 4, No. 1, 2011, pp. 250-256.

[9] S. Ramgopal, K. Ramesh, N. Maasi Reddy, A. Chakradhar and K. C. Rajanna, "Metal Nitrate Driven Nitro Hunsdiecker Reaction with $\alpha, \beta$-Unsaturated Carboxylic Acids under Solvent-Free Conditions," Tetrahedron Letters, Vol. 48, No. 23, 2007, pp. 4043-4045. doi:10.1016/j.tetlet.2007.04.026

[10] K. C. Rajanna, N. Maasi Reddy, M. Rajender Reddy and P. K. Saiprakash, "Micellar Mediated Halodecarboxylation of $\alpha, \beta$-Unsaturated Aliphatic and Aromatic Carboxylic Acids-A Novel Green Hunsdiecker-Borodin Reaction," Journal of Dispersion Science and Technology, Vol. 28, No. 4, 2007, pp. 613-616. doi:10.1080/01932690701282690

[11] A. Vilsmeier and A. Haack, "Über die Einwirkung von Halogenphosphor auf Alkyl-formanilide. Eine neue Methode zur Darstellung Sekundärer und Tertiärer p-Alkylamino-benzaldehyde," Berichte der Deutschen Chemischen Gesellschaft (A and B Series), Vol. 60, No. 1, 1927, pp. 119-122.

[12] W. Su, Y. Weng, L. Jiang, Y. Yang, L. Zhao, Z. Chen and Z. Li, "Recent Progress in the Use of Vilsmeier-Type Reagents," Organic Preparations and Procedures International, Vol. 42, No. 6, 2010, pp. 503-555. doi:10.1080/00304948.2010.513911

[13] I. M. A. Awad, "Studies on the Vilsmeier-Haack Reaction. Part XIII: Novel Heterocyclo-Substituted 4,4'-Bi-pyrazolyl Dithiocarbamate Derivatives," Chemical Technology and Biotechnology, Vol. 56, No. 4, 1992, pp. 339-345.

[14] I. M. A. Awad, "Studies in the Vilsmeier-Haack Reaction, Part VII: Synthesis and Reaction of 3-Methyl-1-phenyl-4acetyl Hydrazono 2-Pyrazoline-5-one(-5-thione)," Monatshefte für Chemie, Vol. 121, No. 12, 1990, pp. 10231030.

[15] G. A. Olah and St. J. Kuhn, "Friedls Craft's and Related Reactions," John Wiley and Sons, New York, 1964. doi: $10.1002 /$ jctb. 280560403

[16] H. Ulrich, "The Chemistry of Imidoyl Halides," Plenum Press, New York, 1968.

[17] R. Bonnet, "Imidoylhalides," In: S. Patai, Ed., The Chemistry of the Carbon Nitrogen Double Bond, John Wiley \& Sons, New York, 1970.

[18] G. F. Smith, "Indoles. Part I. The Formylation of Indole and Some Reactions of 3-Formylindole," Journal of the Chemical Society, Vol. 1, 1954, pp. 3842-3846.

[19] S. Alumi, P. Linda, G. Marino, S. Santine and G. Salvelli, "The Mechanism of the Vilsmeier-Haack Reaction. Part
II. A Kinetic Study of the Formylation of Thiophen Derivatives with Dimethylformamide and Phosphorus OxyChloride or Carbonyl Chloride in 1,2-Dichloroethane," Journal of the Chemical Society, Perkin Transactions, Vol. 2, No. 14, 1972, pp. 2070-2073. doi:10.1039/p29720002070

[20] Z. Arnold and A. Holy, "Synthetic Reactions of Dimethylformamide. XIV. Some New Findings on Adducts of the Vilsmeier-Haack Type," Collection of Czechoslovak Chemical Communications, Vol. 27, 1962, pp. 28862897.

[21] G. J. Martin, S. Poignant and M. L. Filleux and M. T. Quemeneeuer, "Recherches sur la Reaction de VilsmeierHaack Etude du Mecanisme de Formation du Complexe par des Mesures Cinetiques en Resonance Magnetique Nucleaire," Tetrahedron Letters, Vol. 11, No. 58, 1970, pp. 5061-5064. doi:10.1016/S0040-4039(00)96986-7

[22] G. J. Martin and S. Poignant, "Nuclear Magnetic Resonance Investigations of Carbonium Ion Intermediates. Part I. Kinetics and Mechanism of Formation of the VilsMeier-Haack Reagent," Journal of the Chemical Society, Perkin Transactions, Vol. 2, 1972, pp. 1964-1966.

[23] K. C. Rajanna, M. M. Ali, F. Solomon and P. K. Saiprakash, "Vilsmeier-Haack Formylation of Coumarin Derivatives. A Solvent Dependent Kinetic Study," International Journal of Chemical Kinetics, Vol. 28, No. 12, 1996, pp. 865-872.

doi:10.1002/(SICI)1097-4601(1996)28:12<865::AID-KI $\mathrm{N} 1>3.0 . \mathrm{CO} ; 2-\mathrm{L}$

[24] J. Quiroga, J. Trilleras, B. Insuasty, R. Abonı'a, M. Nogueras, A. Marchal and J. Cobo, "Regioselective Formylation of Pyrazolo[3,4-b]pyridine and Pyrazolo[1,5-a]pyrimidine Systems Using Vilsmeier-Haack Conditions," Tetrahedron Letters, 2008, Vol. 49, No. 17, pp. 26892691. doi:10.1016/j.tetlet.2008.02.166

[25] C. M. Marson and P. R. Giles, "Synthesis Using Vilsmeier Reagents," CRC Press, Boca Raton, 1994.

[26] T. J. Mason and J. P. Lorimer, "Sonochemistry. Theory, Applications and Uses of Ultrasound in Chemistry," Ellis Harwood, New York, 1989.

[27] T. J. Mason, Chemistry with Ultra Sound," Critical Reports in Applied Chemistry No. 28, Society for Chemical Industry, 1990.

[28] M. H. Entezari and A. A. Shameli, "Phase-Transfer Catalysis and Ultrasonic Waves I. Cannizzaro Reaction," Ultrasonics Sonochem, Vol. 7, 2000, pp. 169-172. 